\title{
How Social Customs Restrict EU Accession Effects on Female Labor Participation in Agricultural Production in Rural Adana, Turkey: A Simulation Analysis
}

\author{
Takeshi Maru'
}

\begin{abstract}
This study investigates the relationship between female labor participation and social customs in a rural area of Mediterranean Turkey, and examines how and to what extent existing social customs restricting female labor supply would constrain the effects on agricultural production and farm behavior of Turkey's accession to the European Union (EU). Based on the results obtained in a field survey, a household model incorporating social customs is constructed that demonstrates the effects of divergence from standard female labor participation rates in crop production. Using this model, computable general equilibrium simulation analyses of Turkey's accession to the EU are conducted. The results show that although social customs may restrain agricultural production by limiting female labor participation in crop production, their restraining effects are not as large as the effects of the changed production circumstances that would be caused by Turkey's accession to the EU.
\end{abstract}

Key words: agricultural household model, female labor participation, Turkey's accession to the European Union, social customs, computable general equilibrium simulation analysis

\section{Introduction}

Turkey's accession to the European Union (EU) has been discussed in many studies that have analyzed its possible effects on the Turkish economy. However, the accession negotiation procedure has stalled due to current conditions in the EU and Turkey. The EU is now suffering from economic problems such as intra-EU income disparity partly caused by the union's rapid enlargement. Turkey's pro-Islamic government policy has been noted by the EU, and it faces political and religious challenges from regional confusion in the Middle East. Nevertheless, it is still important to understand the effect that Turkey's accession to the EU would have on the Turkish economy and on farm households in the country, since agriculture is an important industry in rural Turkey. Of the studies that have involved simulations of the effects of accession on domestic industries, those on agriculture are limited. Çakmak (2004), Kagatsume
(2006), Kameyama et al. (2007), and van Leeuwen et al. (2011) conducted detailed analyses that considered differences among products. The first three of these studies concluded that EU accession made animal husbandry worse off, in contrast with crop production, which improved, whereas van Leeuwen et al. (2011) came to the opposite conclusion. However, all these studies were based on a macro perspective and did not focus on the effects of agricultural policy changes on farm households and their responses to these changes. Local-level analyses are also needed that consider farm household behavior.

Furthermore, if accession to the EU widens productivity differences between crop production and livestock production, as Çakmak (2004) and other studies concluded, this might have effects on the labor participation rates of female household members, who generally work on animal husbandry in accordance with social customs as the sociological and anthropological lit-

\footnotetext{
${ }^{1}$ Institute of Economic Research, Hitotsubashi University marl@ier.hit-u.ac.jp
} 
erature has pointed out. ${ }^{1)}$ Even if EU accession could improve crop production circumstances, social customs might restrain the effect by preventing female labor from joining in crop production. However, although EU accession could have effects on labor allocation in agriculture, previous studies have not analyzed this issue.

There have been some studies that treated impacts of trade and policy reforms on gender issues with computable general equilibrium (CGE) simulation models (for example, Fontana and Wood, 2000; Arndt et al., 2006; Filipski et al., 2011). However, these studies generally do not explicitly include social customs in their model specifications and do not examine their effects. For example, Filipski et al. (2011) illustrated gender differences in the effects of free trade on labor by focusing on the composition of elasticity among many types of work. However, this method cannot clearly distinguish between the effects of social customs and other factors such as differences caused by physical characteristics. Following Akerlof (1980), a series of previous studies has treated social customs theoretically in line with the sociological and anthropological literature. For instance, Vendrik (2003) analyzed how social norms in labor matters change according to individual beliefs about these norms and the feedback from collective actions. CGE simulations that treat impacts of trade and policy reforms on gender issues should integrate this type of theoretical framework, since CGE analysis is suitable for evaluating the effects of policies and other changes and is useful for policy makers in grasping the relative importance of various impacts.

Therefore, the objective of this study was set to investigate the relationship between female labor participation and social customs in a rural area of Mediterranean Turkey, and to examine how and to what extent existing social customs restricting female labor supply would constrain the effects on agricultural production and farm behavior of Turkey's accession to the EU, using an agricultural household model framework with social customs and CGE modeling.

Here, we should be aware of the possibility that the feasibility of accession to the EU might be affected when the effects of social customs restrictions are considered. The impact of social customs can be regarded as an effect that delays the accession; the accession might not happen until these social customs have disappeared, if the $\mathrm{EU}$ views them as an important issue. This would decrease the need to consider the effect of social customs and even the EU accession itself. Nevertheless, it is still important to measure the constraining effect of social customs on the impact of accession on agricultural production, if it exists, so that policy makers can consider the extent of its economic influence and its pros and cons. This study will contribute to the literature on CGE simulations that treats impacts of trade and policy reforms on gender issues and that treats Turkey's accession to the EU, by focusing on the constraining effect of social customs on the impact of $\mathrm{EU}$ accession on agriculture in Turkey.

In this study, we use data obtained from a farm household and village survey conducted in Adana Prefecture. According to the Turkish Statistical Institute (2007), the production value of the crop sector in Adana is the fifth largest of 81 prefectures overall in Turkey, and Adana has the largest agricultural land area and midlevel productivity of crop sectors in the Mediterranean region, which has the largest agricultural production value in Turkey. Since farm households in Adana can be considered as typical of households in more prosperous regions and a large number of these households would be affected by EU accession, it is appropriate to measure the effects of accession with the data surveyed in Adana. However, it must be noted that the study site is not representative of the whole rural area of Turkey and the results obtained in this study cannot be applied to all other areas.

In Section 2, the general situation of the study site is explained. A household model with social customs is constructed in Section 3, and a series of CGE simulation analyses is conducted in Section 4 . Section 5 offers concluding remarks.

\section{Study Site and Social Customs}

\section{1) Social customs in agricultural work}

Patterns of low female labor participation rates and labor division by gender in accordance with levels of economic development can be seen in many countries. However, the factor

1) See, for example, Morvaridi $(1992,1993)$ and Hoshiyama (2003). 
Table 1. Basic information on sample households $(n=34)$

\begin{tabular}{lr}
\hline Average age of household head (years) & 48.0 \\
Average number of household members (persons) & 5.2 \\
Average size of managed land (ha) & 16.0 \\
Number of livestock-keeping households (households) & 6 \\
Average value of crop products (1,000 TL) & 62.7 \\
Average value of livestock products (1,000 TL) & 0.3 \\
Average value of livestock sold (1,000 TL) & 0.1 \\
Average household labor on crops (males*days) & 58.2 \\
Average household labor on crops (females*days) & 2.0 \\
Average household labor on livestock (males*days) & 21.5 \\
Average household labor on livestock (females*days) & 9.7 \\
Average household labor in off-farm work (males*days) & 90.3 \\
Number of households that have male members working in & 13 \\
off-farm work (households) & \\
Number of households that have female members working & 2 \\
in off-farm work (households) & \\
\hline Source: Farm survey. & \\
Note: Turkish lira (TL) is expressed in present currency notation. One \\
euro equaled around 2.9 TL as of April 2014.
\end{tabular}

specific to Turkey and other countries in the Middle East is that there has been a traditional social norm that females should avoid being in contact with males except for members of the same household or relatives. In following this norm, the division of labor in which men work outside and women engage in housework is customarily strengthened, while betraying this custom is considered to be shameful behavior. This labor division seems to be alive even in recent years. Although the female labor participation rate increased slightly from $23.3 \%$ in 2004 to $29.5 \%$ in 2012 , it is still much lower than in other OECD countries (Turkish Statistical Institute, 2013). According to a survey conducted by the Ministry of Family and Social Policies of Turkey in 2011, around $19.4 \%$ of those polled denied women's right to work; the percentage was $28.1 \%$ in male respondents and became higher in the less-westernized eastern part of Turkey. Moreover, "customs and tradition" accounted for about $9.9 \%$ of the reasons given for women's work being seen as unsuitable, while "primary duties of women are child care and housework" accounted for about $58.6 \%$ of responses (Turkish Statistical Institute, 2013).

This labor division also exists in agriculture. Hoshiyama (2003), who conducted a sociological survey in the same lower Çukurova basin, showed that cultivating vegetables and picking cotton are considered work for women in the basin. Hoshiyama (2003) explained why these became tasks for women as follows: cultivating vegetables was originally done in the home garden and this has gradually become considered as a job for females. It was necessary to utilize female labor for economic reasons in the past and therefore female members reconciled social customs with economic necessity and participated in activities such as the harvesting of vegetables and cotton by working only with other females and/or with male household members. Morvaridi (1993), who studied the eastern part of Turkey, showed that the honor of male household members could be compromised if they did women's work, even if the households were poor and females could not work because of illness or injury.

\section{2) Agriculture in the study site}

Adana Prefecture is located in the Mediterranean region of south central Turkey. Two rivers flow through Adana into the Mediterranean Sea. The Çukurova plain in the lower basin has fertile soil, and the middle/upper reaches are hilly areas leading into the Anatolian highland. Irrigation facilities are well developed in the lower basins and the proportion of irrigated villages is high, whereas irrigation facilities are not well developed in the middle/upper reaches. In the lower plain where many irrigation-intro- 
duced villages exist (hereafter, irrigated area), mainly wheat, cotton, maize, citrus, and vegetables are planted. In the past, there were many sheep and goats in addition to cattle; however, in recent years, only some farmers keep a few head of cattle in barns.

In 2003, we conducted a farm household survey, and data from 34 households sampled from two irrigated villages in the Çukurova plain are used in this study. ${ }^{2)}$ Since we could not obtain all the household data required to select farmers randomly in the surveyed villages, we first interviewed farmers found at cafeterias in the villages and then adjusted the number of farmers interviewed to fit the managed land size distribution of the villages at the final stage of the survey. Table 1 shows descriptive statistics for the data of the sampled households.

The average size of the managed land is around 16 ha, which is substantially larger than the country average. In general, a land-lease market exists; lands are frequently leased from people living in cities and multiple-year contracts are common. However, transactions are limited to those living within the villages in the study site, and therefore, the inter-village landlease market can be said to be illiquid.

The number of sampled households that keep livestock is six and the ratio of these to the total is around $18 \%$. According to Maru (2010), there exists a large productivity difference between crop and livestock production in the irrigated areas of Adana, and farmers have tended to stop keeping livestock while the managed land size has increased over time. The data in this study also show a large difference in production values and this may be related to a low livestock-keeping household ratio. The main products sold outside this area are maize, citrus, wheat, and dairy products, although a certain amount of the last two are kept for domestic use.

As for family labor, male members mainly work on crop production, such as plowing, planting, and fertilizing, but also on some animal husbandry tasks. Female members primarily engage in housework and animal husbandry activities such as cleaning barns and feeding livestock, and sometimes planting vegetables. Additionally, females sometimes do small amounts of supplementary work with male members in tasks such as plowing and irrigating when the household manages small plots of land. There seems to be no detailed division of labor with strict sanctions. However, the amount of female crop labor is small. Additionally, the village survey conducted in 2013 revealed that, in some cases, female members needed to have permission from male members to work outside. ${ }^{3)}$ Farmers believe that there are particular types of work that males and females should do exclusively and that letting female members work outside is a sensitive issue that relates to the honor of the family.

Employed workers are mainly engaged in activities such as seeding and harvesting. In many cases, one hired operator with his own machine and dozens of hired laborers complete the harvesting. Among the 34 households surveyed, 13 of the sampled households sent their male members to other farms and sectors. Of these, eight sent their members to other farms as workers. However, the income earned by such employment was only $4.7 \%$ of the expenditure on employing workers. In general, there appears to be a strong demand for workers in the irrigated area of Adana. Furthermore, only two sent female members; $8.3 \%$ of the total income earned by being employed was from females. These two households had three or four children aged around 20 years and all members of each household worked together. In sum, there were few female members employed outside their own farms in this area. Considering the demand for workers in this area, these findings seem to be attributable to social customs as explained above.

There is the possibility that housework and high household income increase shadow prices

2) Villages are not randomly sampled but are selected to represent general characteristics of the study site according to the advice of local counterparts of the research project.

3) Generally, only a few days of outside work due to an urgent need for labor or for economic reasons will be allowed.

4) The reason that detailed labor divisions do not appear and the overall amount of female crop labor is small is as follows: vegetables are nowadays cultivated outside residential areas for the purpose of selling the produce; therefore, it is felt that female members should stop working outside in cases where economic and workforce circumstances are not severe. 
of members and, consequently, decrease female labor participation. Farmers in this area may consider both wages and shadow prices and allocate males to crop production, females to housework and animal husbandry, and hired workers to satisfy labor demands in crop production.

It is difficult to accept that jobs requiring diligent field management and dexterous ability such as hand-picking cotton are not suitable for females. In the study site, harvesting machines for vegetables and tree crops are not well established and there may be room for female household members to work. Decreased hours of housework are expected because of the technological progress of recent years. If female members participate in harvesting, with proper reallocation of housework among members, agricultural production may increase and the utility of households may also increase via the income effect. Nevertheless, farmers seldom let female members participate in crop production. Considering the survey result that permission was required from the household head for the labor participation of female members, an empirical analysis is needed that considers not only wages and shadow prices, but also the effects of social customs.

The southeast Anatolian region, which is the origin of many outside workers in the study area, has experienced development as a result of a government initiative; it is consequently becoming difficult for farmers to employ workers. Çakmak (2004) and other studies expected a relatively large shrinkage in animal husbandry compared with crop production. However, should social customs continue to restrict the participation of female members in crop production, negative effects on this sector could occur because of an insufficient labor supply. Some countermeasures are required if the effects become severe; therefore, the effects of social customs and their restrictions need to be consid- ered in analyzing the effects of EU accession on farmers in the study site.

\section{Model}

\section{1) Introduction of social customs}

Here, the essence of our model containing social customs is explained, based on the information given above. The base model without the social customs restriction module is available in the Appendix.

Social customs concerning female labor participation in crop production are built into the base model.5) In the study site and similar areas, if a household decides on a labor input level that is different from the socially determined level by considering only economic and work force aspects, the utility level of the household will directly decrease if the society imposes penalties or restrictions on the household. Generally, restrictions on inputs are upper-limit restrictions in household models. However, the upper-limit restriction does not directly affect the utility level, and it is difficult to treat it as a problem of deciding the difference of input level from the socially determined level and to consider the possibility of inputs exceeding the socially determined level. In the literature on CGE modeling, the transaction approach has been adopted. ${ }^{6)}$ However, in the case of social customs restrictions for this study, it is complicated to explicate and set up social customs within the transaction approach. In this study, therefore, social customs that directly decrease the utility level by deviating from the socially determined standard input level are introduced. The utility function of the household is modified as

$$
U^{\prime}=U-R,
$$

where $U$ is the usual utility and $R$ is the social customs restriction and is expressed as ${ }^{7)}$

$$
R=\frac{\theta}{2}\left(t_{f}^{C}-\bar{R}\right)^{2}
$$

where $t_{f}^{C}$ is female labor in crop production, $\bar{R}$ is

\footnotetext{
5) More precisely, social customs include various restrictions in addition to that on female labor participation in crop production, such as those on housework. However, to analyze them fully it is necessary to decompose the labor participation structure and to consider housework and other activities, leading to unnecessary complications in the model. The main purpose of this study is to examine how and to what extent existing social customs restricting female labor supply would constrain the effects on agricultural production and farm behavior of Turkey's accession to the EU. Since the results in Section 2 indicate that the restriction of the female labor supply may have a significant impact on crop production, only the social customs restriction on female crop labor is considered in this study.
}

6) See, for example, Hosoe et al. (2010) and Brooks et al. (2010). 
the standard input level of $t_{f}^{C}$ dictated by social customs, and $\theta$ is a parameter that shows the strength of these social customs. Here, $t_{f}^{C}>\bar{R} \geq 0$ is assumed to be the case, based on observed results in the study site. The more $t_{f}^{C}$ is relative to $\bar{R}$, the greater will be the decrease in the utility level; the larger $\theta$ becomes, the more steeply the utility level decreases. In other words, when $\theta$ is large, the societal penalty strongly decreases the utility level even if the deviation from $\bar{R}$ is very small. Furthermore, in the case where female members working outside is regarded with maximal shame $(\bar{R}=0)$, only a small amount of outside work for crop production by female members significantly reduces the household utility level.

On the other hand, when $\theta$ is not very large, more deviations can be accepted. In this case, the following pattern can occur in the society where the situation of female members working outside is regarded with shame. If there is a sudden lack of labor, one or two days of outside work by female members in crop production with male members can be accepted. However, if female labor participation is scheduled for more than a few days, this means that the household makes female members work outside even though the work is substitutable with employed labor; therefore, the utility level decreases further. Moreover, if female labor participation is scheduled permanently, female members have to put working outside above housework and animal husbandry, activities that are considered to be important work for women. This leads the household to identify its behavior as shameful.

\section{2) Interpretation of social customs}

By including social customs restrictions in the model, the utility maximization problem expressed by $\Psi$ changes with time allocation equations for female members $\partial \Psi / \partial t_{f}^{C}=0$ to

$$
p^{C} \frac{\partial F^{C}}{\partial t_{f}^{C}}=p_{f}^{*}+\frac{\theta\left(t_{f}^{C}-\bar{R}\right)}{\mu_{\pi}},
$$

where $p^{C}$ is the price of crop products, $F^{C}$ denotes the crop production function, $p_{f}^{*}\left(=\mu_{f} / \mu_{\pi}\right)$ is the normal shadow price of female labor, $\mu_{\pi}$ is the marginal utility of income and $\mu_{f}$ is the marginal utility of time consumption. The shadow price of female labor in crop production $p_{f}^{C *}$ contains a new part arising from the social customs restriction, in addition to $p_{f}^{*}$, while $t_{f}^{C}$ in the second term of the right-hand side of this equation makes the marginal valuation of female labor slope upward from left to right. The greater the positive response to social customs $\theta$ becomes, the larger is the slope of the shadow price of female labor in crop production. By contrast, the shadow price decreases if the standard level $\bar{R}$ is a positive value.

Female labor in crop production is generally considered unfavorable in our study site; therefore, $\bar{R}$ becomes zero. ${ }^{8)}$ If $\theta$ does not have a large effect on $\mu_{\pi}$ or $\mu_{f}$, then the shadow price $p_{f}^{C *}$ increases substantially and $t_{f}^{C}$ approaches zero in the case of strict customs.

Even though the marginal product value curve of female labor goes upward from an increase of inputs or an increase in productivity, the amount of female labor in crop production may not increase compared with the case of no social customs if parts of the second term of the shadow price other than $t_{f}^{C}$ increase. ${ }^{9)}$ If $\theta \rightarrow 0$, in contrast, the increase of female labor participation in crop production may be on terms close to the case of the normal shadow price.

If social customs obstruct female labor participation in crop production, females must increase their leisure consumption or their labor supply in livestock production, which has low productivity compared with crop production. This results in a decline of $\mu_{f}$ and an increase of $\mu_{\pi}$ resulting from a decrease in income because of an

7) Some studies such as Kevane and Wydick (2001) and Fletschner and Carter (2008) use this type of quadratic functional form for social customs restrictions on female labor.

8) In the case when $\bar{R}$ is zero, this $\bar{R}$ does not have to be determined at the initial point of the analysis. However, it should be noted that zero is the value for the study site of the present analysis. When it comes to the cases of considering differences in norms, heterogeneity among households, and dynamic factors, then the value of $\bar{R}$ is important.

9) Labor in the household is usually unpaid; thus, labor with low productivity can be considered to be an input into housework. In the study site, however, even households with relatively small farm sizes utilized employed labor in crop production rather than female members, although these households did have female members active in animal husbandry. The increase of the shadow price of female labor caused by social customs can be considered as one reason for this. 
increase in the payments for employees and leisure consumption. This means a drop in the normal shadow price $p_{f}^{*}$. If this happens, social customs suppress the shadow price of females as a whole..$^{10)}$

\section{Simulation}

\section{1) Basic settings}

We conducted simulation analyses based on the household survey data discussed above. Using the model containing the social customs module in Section 3, we simulated how and to what extent the effects of Turkey's accession to the EU on farm households differ between the case where the social customs discussed above exist and the case where they do not.

The social accounting matrix (SAM) was constructed for our CGE modeling. ${ }^{11}$ SAM records transactions of goods and services among industries and agents, and can analyze whole economies in consideration of mutual interactions. SAM can be made at various levels such as countries, regions, and villages and, as shown in Dyer et al. (2006) and Taylor et al. (1999), SAM can be utilized as a database of CGE analyses with datasets from farm household surveys. In this study, data were collected at a whole-village level as a database for the CGE modeling, and then SAM of a representative household was produced.

The data are basically the same as the results of the farm household survey in Section 2. ${ }^{12}$ ) With the assumption of linear homogeneity, the factor shares were used for exponents of the Cobb-Douglas production functions. To calculate the factor share of female labor, the shadow price is needed. It is desirable to estimate the shadow price econometrically. However, as mentioned in Section 2, the numbers of farmers managing animal husbandry and farmers where female members participate in labor were small; therefore, we needed to adopt other methods. Maru's (2010) survey of Adana Prefecture showed that there were no significant differences between the marginal productivity of own farm labor and market wages for either male or female members. ${ }^{13)}$ Therefore, the present study assumed that the initial value of the male wage and that of the shadow price of the overall female labor supply were equal to the market wage. ${ }^{14)}$

Each shadow price for a female member in crop and livestock production is affected by social customs at the time of the SAM construction. Hence, we needed to set up values of the parameters $\bar{R}$ and $\theta$ at this time. We assumed that $\bar{R}=0$ because of the norm that there should be no female labor participation in crop production. It is desirable to define the value of $\theta$ using econometric methods. Because this is very difficult, we set the value of $\theta$ in a convenient way. EU accession simulations were conducted considering the case with no social customs restriction $(\theta=0)$, the weak restriction case $(\theta=0.2$ : the shadow price of crop production is around 1.4 times higher than that of livestock, in the case of working two days), and the strong restriction case $(\theta=0.4$ : the shadow price of crop production is around 1.9 times higher than that of livestock, in the case of working two days). ${ }^{15}$

It is preferable to estimate the elasticity of

10) It should be noted that this social customs restriction is different from the usual disutility due to physical or psychological pain caused by labor participation.

11) See Sadoulet and de Janvry (1995) for details of the SAM.

12) The sample size of 34 is small because it is difficult to include complete data about households. This is common in other village-level CGE studies such as Dyer et al. (2006) and Taylor et al. (1999).

13) In Table 5 of Maru (2010), the $t$-test does not reject the null hypothesis of no differences between the marginal productivity of own farm labor and market wages at the $10 \%$ level for either male or female members in both irrigated and rain-fed areas.

14) For a male member, a certain rate of machine operating is included in labor employment. By following Maru (2010), the market wage for a male was set with attention to the labor type.

15) According to the survey results indicating not very strict social customs restriction in the study site, the value of $\theta$ was set to express the restriction level where two or three days of female labor on crop production were considered acceptable. In the model, each additional work day of female crop labor increases its shadow price. Setting $\theta=0.2$ or $\theta=0.4$ might represent being acceptable as guest labor during a sudden shortage. If we set $\theta=4$, only one day of work makes the shadow price of female crop labor around five times higher than that of other workers. If the female member works dozens of days on crop production without an expensive shadow price (two times for example), the parameter value needs to be much lower, like $\theta=0.00001$. 
substitution $\sigma$ in the labor market by econometric methods. However, for the same reason as for $\theta$, $\sigma$ was set at 0.99 because Taylor et al. (1999) assumed $\sigma \approx 1$ in their main results. ${ }^{16)}$

After making an SAM for each $\theta$, data on each SAM were taken as the initial equilibrium for each social customs restriction case $(\theta=0$, $\theta=0.2$, and $\theta=0.4$ ), and calibration was conducted to obtain parameters. Here, it must be noted that each case of $\theta$ has a different initial equilibrium; and that the initial equilibrium for each $\theta$ supposes the situation where Turkey's accession to the EU is not realized. Analyses were conducted by using the General Algebraic Modeling System (GAMS) software.

\section{2) Results: Changes with Turkey's acces-} sion to the EU

Here, we simulated how and to what extent agricultural production and farm behavior changed from the initial equilibrium for each case of $\theta$ after Turkey's accession to the EU. If Turkey joins the EU, its agricultural policy will change to the Common Agricultural Policy (CAP) of the EU. Since the exact accession year cannot be assumed under the current situation, it was assumed as an hypothesis that there were no great changes in the situations of rural areas as surveyed in 2003 and the accession made in some future year. ${ }^{17)}$ It was also assumed that external conditions except for the social customs and price/policy changes were constant in postaccession equilibrium. ${ }^{18)}$

The current EU agricultural policy has a payment scheme linked to production in addition to the Single Area Payment Scheme (SAPS) after the CAP "Health Check." However, requirements for its allotment to newly acceded countries are strict, and the share of the productionlinked payment scheme is basically small in these countries. Thus, only SAPS was considered in this study. SAPS entails income transfers to farm households as land-based subsidies. According to the USDA (2004), the average value of SAPS payments in countries acceded to the EU in 2004 was 47.6 euros per ha. It was supposed that the same value would be paid to farmers in the case of Turkey's accession, and the value was adjusted by the consumer price index and used in simulations.

Postaccession prices of crop and livestock products at the farm gate, $p^{C^{\prime}}$ and $p^{L^{\prime}}$, respectively, are calculated from border prices, accounting for transportation and other costs because tariffs for agricultural products will be diminished. In this study, crop products were brought together and treated as one product. The same treatment was applied to livestock products. The ratios of products were assumed to be the same and then aggregated crop and livestock product prices were calculated. Using the FAOSTAT and HGCA data, $p^{C^{\prime}}$ and $p^{L^{\prime}}$ were around 1.2 and 0.8 times the preaccession prices. ${ }^{19)}$

Finally, social customs restrictions after accession were assumed to be at the same level as the initial equilibrium level. Table 2 shows the simulation results of changes with Turkey's accession to the EU for each $\theta$ case.

16) Results of CGE simulation cannot be regarded as reliable when vectors of changes in values reverse when the value of a parameter is changed. For sensitivity analysis, the cases of $\sigma=0.5$ and $\sigma=3$ were simulated according to Taylor et al. (1999).

17) Since the accession procedure has not been proceeding, there will be a lag of around 20 years between the surveyed year and accession year, 2023, at the earliest. Attention should be paid if the composition of crop production in this area changes significantly due to major transformations in production circumstances such as introduction of irrigation or EU accession. According to statistical data taken from the Turkish Statistical Institute website (taken on November 5, 2013), the compounded average of percent change of average amounts produced in Adana from 2003-2005 to 2010-2012 was - 3.58\% for wheat, $1.04 \%$ for maize, and $0.39 \%$ for citrus (orange, mandarin, and lemon). Here, we must note that these values were the prefectural average and included effects of rain-fed villages and villages where irrigation facilities were recently introduced, and the relatively high percentage change in wheat might be affected by this. The study site has been a well-developed area in terms of irrigation facilities since the 1960s, and therefore it seems there have been no great changes in production trends. Additionally, a lag of around 10 years was shown in previous studies such as Taylor et al. (1999).

18) The Turkish government initiated the Agricultural Reform Implementation Project (ARIP) and switched its policy from a price support policy to a direct income support policy in 2001. However, because of a poor reception from farmers, the government went back to a price policy with a premium for certain produce (OECD, 2011). This study contains direct payment in initial equilibrium since there was direct payment in the surveyed year, 2003 
Table 2. Simulation results: changes with Turkey's accession to the EU $(\sigma=0.99)$

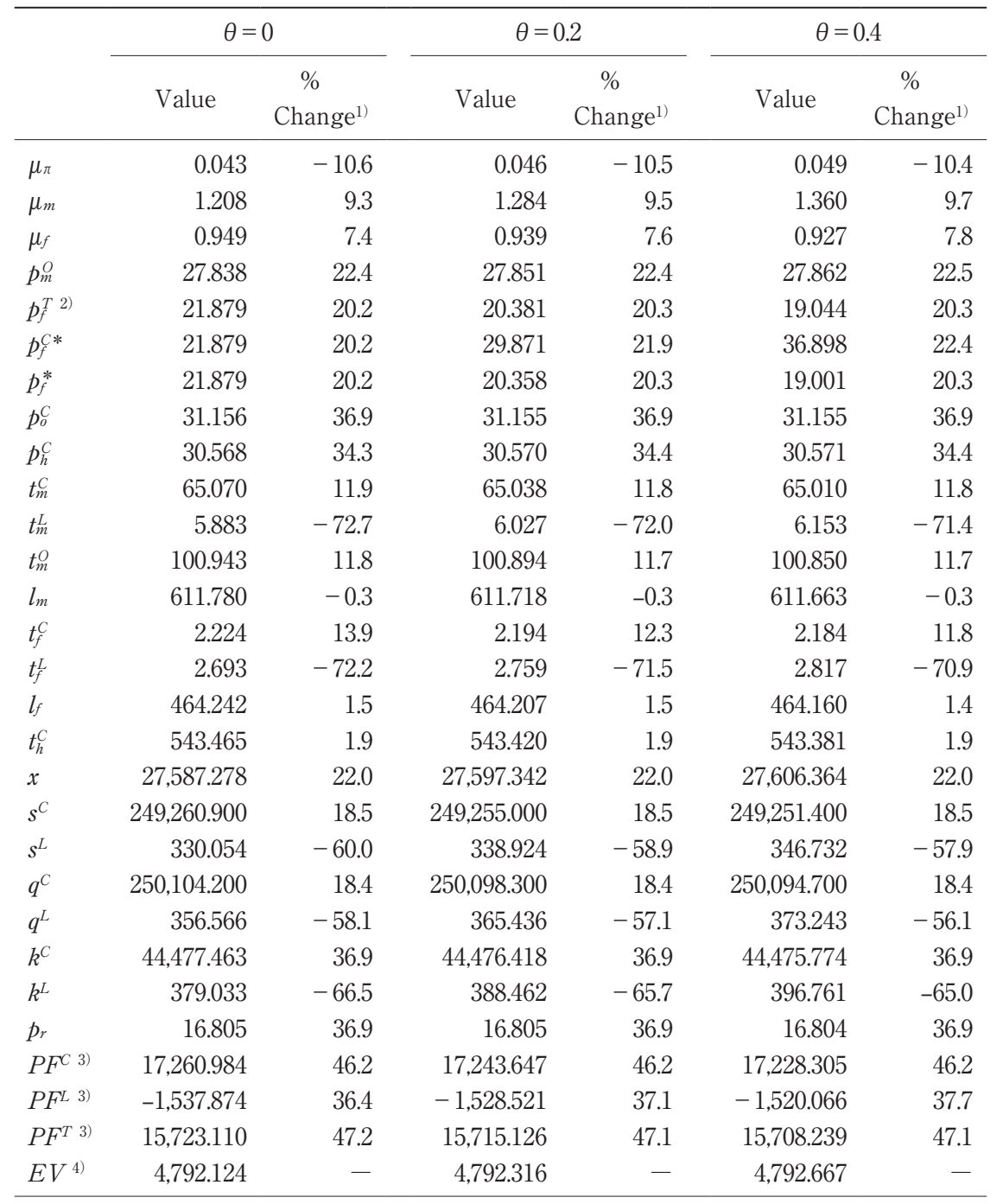

Note: 1) This is the percentage change from the initial equilibrium for each case of $\theta$.

2) $p_{f}^{T}$, the shadow price of overall female time, is a weighted average of $p_{f}^{C *}$ and $p_{f}^{*}$.

3) $P F^{C}, P F^{L}$, and $P F^{T}$ are productive profits of crops, livestock, and overall production.

4) $E V$ means equivalent variation.

The results indicate that the increase in the crop product price and the drop in the livestock product price make the farmer concentrate on crop production, while the shadow prices of family labor increase (around 20\% from the initial equilibrium) via the large increase in profits.
The results show that there is a difference between the shadow price of female labor in crop production compared with livestock production and a decrease in the overall shadow price of female labor resulting from the social customs restriction. Female labor shifts from

19) This increase of crop prices in the simulation can be considered as the reason that the price of oranges, one of the main products in the study site, is currently slumping because of the oversupply of oranges in the local market. The abolition of import duties (708 euros/ton as of April 2013) will increase exports of oranges and the price received by farmers. 
Table 3. Simulation results: changes with Turkey's accession to the EU and the disappearance of social customs $(\sigma=0.99)$

\begin{tabular}{|c|c|c|c|c|}
\hline & \multicolumn{2}{|c|}{$\Delta \theta=(0.2 \rightarrow 0)^{1)}$} & \multicolumn{2}{|c|}{$\Delta \theta=(0.4 \rightarrow 0)^{2)}$} \\
\hline & Value & $\begin{array}{c}\% \\
\text { Change }^{3)}\end{array}$ & Value & $\begin{array}{c}\% \\
\text { Change }^{3)}\end{array}$ \\
\hline$\mu_{\pi}$ & 0.046 & -10.6 & 0.049 & -10.5 \\
\hline$\mu_{m}$ & 1.284 & 9.5 & 1.360 & 9.7 \\
\hline$\mu_{f}$ & 0.941 & 7.8 & 0.931 & 8.3 \\
\hline$p_{m}^{O}$ & 27.866 & 22.5 & 27.896 & 22.6 \\
\hline$p_{f}^{T}{ }^{4)}$ & 20.414 & 20.5 & 19.106 & 20.7 \\
\hline$p_{f}^{C *}$ & 20.414 & -16.7 & 19.106 & -36.6 \\
\hline$p_{f}^{*}$ & 20.414 & 20.6 & 19.106 & 21.0 \\
\hline$p_{o}^{C}$ & 31.174 & 37.0 & 31.195 & 37.1 \\
\hline$p_{h}^{C}$ & 30.588 & 34.4 & 30.610 & 34.5 \\
\hline$t_{m}^{C}$ & 65.042 & 11.8 & 65.017 & 11.8 \\
\hline$t_{m}^{L}$ & 6.016 & -72.0 & 6.132 & -71.5 \\
\hline$t_{m}^{O}$ & 100.899 & 11.7 & 100.861 & 11.7 \\
\hline$l_{m}$ & 611.720 & -0.3 & 611.666 & -0.3 \\
\hline$t_{f}^{C}$ & 3.212 & 64.5 & 4.223 & 116.2 \\
\hline$t_{f}^{L}$ & 2.748 & -71.6 & 2.795 & -71.1 \\
\hline$l_{f}$ & 463.200 & 1.2 & 462.142 & 1.0 \\
\hline$t_{h}^{C}$ & 543.425 & 1.9 & 543.390 & 1.9 \\
\hline$x$ & $27,612.846$ & 22.1 & $27,639.407$ & 22.2 \\
\hline$s^{C}$ & $249,407.400$ & 18.5 & $249,575.600$ & 18.6 \\
\hline$s^{L}$ & 338.505 & -58.9 & 345.898 & -58.0 \\
\hline$q^{C}$ & $250,250.800$ & 18.5 & $250,418.900$ & 18.5 \\
\hline$q^{L}$ & 365.017 & -57.1 & 372.409 & -56.2 \\
\hline$k^{C}$ & $44,503.529$ & 37.0 & $44,533.436$ & 37.1 \\
\hline$k^{L}$ & 388.017 & -65.8 & 395.875 & -65.1 \\
\hline$p_{r}$ & 16.815 & 37.0 & 16.826 & 37.1 \\
\hline$P F^{C}$ 5) & $17,255.967$ & 46.3 & $17,254.489$ & 46.4 \\
\hline$P F^{L}$ 5) & $-1,528.768$ & 37.1 & $-1,520.567$ & 37.7 \\
\hline$P F^{T}$ 5) & $15,727.199$ & 47.3 & $15,733.922$ & 47.3 \\
\hline$E V^{6)}$ & $4,804.594$ & - & $4,819.449$ & - \\
\hline
\end{tabular}

Note: 1) This is the subsequent simulation of the case of $\theta=0.2$ in Table 2, and " $\Delta \theta=(0.2 \rightarrow 0)$ " means the disappearance of social customs from $\theta=0.2$ to $\theta=0$.

2) This is the subsequent simulation of the case of $\theta=0.4$ in Table 2, and " $\Delta \theta=(0.4 \rightarrow 0)$ " means the disappearance of social customs from $\theta=0.4$ to $\theta=0$.

3) This is the percentage change from the initial equilibrium for each case of $\theta$.

4) $p_{f}^{T}$, the shadow price of overall female time, is a weighted average of $p_{f}^{C *}$ and $p_{f}^{*}$.

5) $P F^{C}, P F^{L}$, and $P F^{T}$ are productive profits of crops, livestock, and overall production.

6) $E V$ means equivalent variation. 
animal husbandry to crop production, but the shift is smaller in the restricted case.

Specialization in crop production largely increases total profit (about 50\% from the initial equilibrium). However, the increase in profit from crop production weakens in the case of higher $\theta$. This indicates that the social customs restriction might cancel out the income-augmenting effect of the improvement in management circumstances caused by EU accession and hence suppress agricultural production. However, this might be caused by settings of the initial equilibrium, because there is little difference in the percentage change from the initial equilibrium between the case of restriction and that of nonrestriction. Additionally, it must be noted that the decrease caused by the social customs restriction is very small compared with the total growth caused by EU accession.

As for equivalent variation, this value increases in the case that the social customs restriction is valid and strong. However, the increase is very small compared with the overall increased effects caused by EU accession. Again, this might be caused by settings of the initial equilibrium. It was necessary to judge the social customs restriction after conducting another simulation that accounted for the effects of the disappearance of social customs. ${ }^{20)}$

\section{3) Results: Changes with the disappear- ance of social customs}

In the following simulation, we estimated how the disappearance of social customs after Turkey's EU accession changed female labor participation in crop production and the farm economy. This simulation captured the composite effects of the disappearance of social customs and Turkey's accession to the EU for each case of $\theta$; and therefore estimated the effect of the disappearance of social customs through the shift in equilibrium from the results obtained in the former subsection. ${ }^{21)}$ It was assumed that the value of $\theta$ in each case changed to zero, which meant that the shadow price of female crop labor became $p_{f}^{*}$ after the simulation conducted in the previous subsection. The results obtained appear in Table $3{ }^{22}$

For female labor, the larger the value of $\theta$ that was assumed, the greater was the increase in participation in crop production (in the case of $\theta=0.4$, there was a 104.4 percentage point increase from the results in Table 2), and the less was the participation in animal husbandry and leisure consumption. Furthermore, the capital input increased with the increase of female crop labor, and the production amount increased from the results in Table 2 . As a result, total profit grew (in the case of $\theta=0.4$, there was a 0.2 percentage point increase from the results in Table 2) and exceeded the total profit in the nonrestricted case $(\theta=0$ from the beginning). It is difficult to conclude simply that the disappearance of the social customs restriction makes agricultural production more efficient. However, it is confirmed that an increase in female labor participation in crop production leads to increases in agricultural production and profit.

The results also show that the total shadow price of female members increased slightly from the results in Table 2 . This can be seen as a result of a relatively large increase in the marginal utility of time consumption compared with the marginal utility of income because of a decrease in leisure consumption and an increase in goods consumption with profit growth.

As for equivalent variation, this value increased in the case that the social customs restriction disappeared (in the case of $\theta=0.4$, the increase was $0.6 \%$ over the results in Table 2 ). It can be said that the effects of increasing goods consumption are larger than those of decreasing leisure consumption because of female labor participation in crop production. However, the increased effects of the disappearance of the social customs restriction are very small compared with the overall increases caused by the

20) Discussion is restricted here because of a lack of space, but the results of sensitivity analysis showed no large directional differences in changes in female labor participation and changes in the shadow price (for example, $p_{f}^{*}=36.699$ for the case $\sigma=0.5$ and $\theta=0.4$, and $p_{f}^{*}=37.324$ for the case $\sigma=3$ and $\theta=0.4$ ).

21) As mentioned in Section 2, the effects of social customs and their restrictions need to be considered in analyzing the effects of EU accession on farmers in the study site. Therefore, we undertook the simulation in this way, instead of simulating how the disappearance of social customs would change female crop labor and the farm economy in Turkey without EU accession.

22) The cases of " $\Delta \theta=(0.2 \rightarrow 0)$ " and " $\Delta \theta=(0.4 \rightarrow 0)$ " in Table 3 are the succeeding simulations of those of $\theta=0.2$ and $\theta=0.4$ in Table 2 , respectively. 
EU accession effect. It can be said that the disappearance of social customs regarding female labor participation in the irrigated areas of Adana Prefecture would not have a strong impact compared with the effect of improvements in the production environment from an economic point of view, even though it is an important issue for gender studies. ${ }^{23)}$

It should be noted that these simulation results depend on the production techniques of farmers at the time of the initial equilibrium. Farmers were using a certain amount of female labor at the initial equilibrium. This can be considered as the farmers' will to use this amount of female labor, even though social customs exist, and it means that female labor is technically important for crop production. Therefore, the stricter the restriction is, the greater female labor participation will be in the event of the disappearance of social customs. These findings indicate that where these kinds of social customs restrictions exist, simulation results may be quite distorted if there is no account of these restrictions in the empirical analyses.

\section{Conclusions}

In this study, we investigated the relationship between female labor participation and social customs in a rural area of Mediterranean Turkey, and examined how and to what extent existing social customs restricting female labor supply would constrain the effects on agricultural production and farm behavior of Turkey's accession to the EU. It is expected that crop production will become more prosperous because of the relative increase in crop product prices resulting from EU accession. The shadow price of female crop labor will increase where social customs restrictions exist, and profits of crop production will decrease compared with the case of no restriction from the beginning. Additionally, female crop labor, production, profits, and equivalent variation will increase in the event of the disappearance of the social customs restriction. Disappearance of the social customs restriction is expected to promote technical changes that will promote further female labor participation.
However, the values of equivalent variation and other variables related to profits in our simulation results show that the economic impact of the disappearance of the social customs restriction on agricultural production are not large compared with the impact of changes in production circumstances caused by EU accession. This indicates that the social customs would not strongly constrain the economic impact of Turkey's accession to the EU and, from this viewpoint, policies that improve agricultural production circumstances become more important. On this basis, it would also be useful to create opportunities for female members to work by improving conditions for livestock production in ways that do not conflict with social customs.

However, there remain certain topics for future investigation. First, the elasticity of substitution/transformation for labor allocation has not been fully considered. Although it is desirable to use constant elasticity of transformation (CET)/substitution (CES) functions in the analysis, simplified specifications have been made. Furthermore, shadow prices and the social customs restriction parameter could not be derived econometrically in the analyses because of data limitations. These issues should be addressed in future studies.

\section{Appendix: Set of Equations in the Base Model}

It is assumed that a village is composed of homogeneous farm households, and one household is extracted from one homogeneous village. This is because the social customs restriction is treated in this study as a deviation from the socially determined norm. If the social customs are considered as a deviation from the average, an equilibrium model from multiple households can alternatively be introduced. Considering the characteristics of the study site, it was appropriate to treat the social customs restriction as a deviation from the norm. The main objective of this study was to analyze how the effects of EU accession on activities of farmers in the Mediterranean region of Turkey differ as a result of the existence of social customs restrictions. It was not the main issue to treat the equilibrium adjustment process among different types of

23) The results of sensitivity analysis show no large directional differences in changes in female labor participation and changes in the shadow price (for example, $p_{f}^{*}=18.962$ for the case $\sigma=0.5$ and $\theta=0.4$, and $p_{f}^{*}=19.417$ for the case $\sigma=3$ and $\theta=0.4$. Jointly considering the results of sensitivity analysis in the simulation of Turkey's accession to the EU, the results obtained in this study are robust to the elasticity of substitution. 
farmers. Furthermore, the household structure was assumed to be based on patriarchy. This involves a male household head making all decisions in the study site, which is different from sub-Saharan African countries where each household member generally manages his/her own fields separately.

The household maximizes utility obtained from the consumption of goods, services, and leisure. A Cobb-Douglas utility function of the household is defined by

$$
U=Z\left(x^{C}, x^{L}, x, t_{f}^{H}, l_{m}, l_{f}\right),
$$

where $x^{C}$ and $x^{L}$ are self-consumptions supplied by crop production $C$ and livestock production $L$ from one's own farm; $x$ is other goods consumption; $t_{f}^{H}$ is hours of housework provided by female member $f$; and $l_{m}$ and $l_{f}$ are leisure hours of male member $m$ and female member $f$, respectively. This utility function is assumed to be constant returns to scale.

Defining $t_{m}^{C}$ and $t_{m}^{L}$ as working hours of $m$ in the crop and livestock production activities on one's own farm, $t_{f}^{C}$ and $t_{f}^{L}$ as working hours of $f$ in the crop and livestock production activities on one's own farm, and $t_{m}^{O}$ as working hours of $m$ at other farms, assuming that there are no female working hours at other farms, then the time constraints of $m$ and $f$, respectively, become

$$
T_{m}=t_{m}^{C}+t_{m}^{L}+t_{m}^{O}+l_{m},
$$

and

$$
T_{f}=t_{f}^{C}+t_{f}^{L}+t_{f}^{H}+l_{f}{ }^{24)}
$$

The Cobb-Douglas crop and livestock production functions of the household are

$$
\begin{gathered}
q^{C}=F^{C}\left(t_{m}^{C}, t_{f}^{C}, t_{h}^{C}, a, k^{C}, E_{k}^{C}\right), \\
q^{L}=F^{L}\left(t_{m}^{L}, t_{f}^{L}, k^{L}, E_{k}^{L}\right),
\end{gathered}
$$

where for crop production, $t_{h}^{C}$ is the input of employed labor to one's own farm, $a$ is the size of the farmland operated, $k^{C}$ are miscellaneous inputs such as fertilizer, and $E_{k}^{C}$ is the capital input. For animal husbandry, $k^{L}$ is miscellaneous inputs such as concentrate diets, and $E_{k}^{L}$ is the capital input. ${ }^{25)}$

Although there is a land-lease market in the village, it was assumed that the total size of village land used was constant. In other words, the land size owned by the representative farmer never changed and equaled its initial size, $E_{a}$, and the amount of land rented in from others living in the city area, $a D_{r}$, was also assumed to be constant:

$$
a=E_{a}+a D_{r} .
$$

Then, the market price of land was determined in response to the productivity of land if the land supply was fixed in the market.

It was assumed that the main products, maize and citrus, are all sold. Wheat and dairy products were assumed to have no fluctuation in self-consumption demand because these products are essential foods. Thus, of all goods produced, $s^{C}$ and $s^{L}$ are sold outside and $x D^{C}$ and $x D^{L}$ are constantly consumed in the village:

$$
\begin{aligned}
& s^{C}=q^{C}-x D^{C}, \\
& s^{L}=q^{L}-x D^{L} .
\end{aligned}
$$

The consumption sector of the households makes expenditure, which consists of values of rented-in land $p_{r} a D_{r}$, purchasing miscellaneous input goods $p_{k}^{C} k D^{C}+p_{k}^{L} k D^{L}$, hired labor $p_{h}^{C} t D_{h}^{C}$, and consuming other goods $p_{x} x D$, equal to income, which consists of values of crop products sold $p^{C} s^{C}$, livestock products sold $p^{L} s^{L}$, and rewards for off-farm work $p_{m}^{O} t_{m}^{O}$. The prices, $p_{r}, p_{k}^{C}$, $p_{k}^{L}, p_{h}^{C}, p_{x}, p^{C}, p^{L}, p_{m}^{O}$, are for land rent, prices of miscellaneous inputs for crop and livestock production, wages for hiring labor, prices of other consumption goods, of crop and livestock products, and wages for being hired, respectively:

$$
\begin{aligned}
p_{r} a D_{r} & +p_{k}^{C} k D^{C}+p_{k}^{L} k D^{L}+p_{h}^{C} t D_{h}^{C}+p_{x} x D \\
& =p^{C} s^{C}+p^{L} s^{L}+p_{m}^{O} t_{m}^{O} .
\end{aligned}
$$

It was assumed that, in the village labor market, there exists an agent who maximizes his profit. $^{26)}$ The agent demands the off-farm labor supplied by male members $t D_{m}^{O}$ from inside the

24) In accordance with the situation of the study site, we limited the types of work to those mentioned above.

25) To focus on the household labor problem, some parts of this model other than labor were simplified: hired labor was limited to that in crop production; other capitals were calculated from their initial quantity; and both production functions were assumed to be constant returns to scale.

26) This may sound strange, but is a common expression of settings in CGE modeling. See, for example, Hosoe $e t$ al. (2010) 
village and the employed labor $t D_{o}^{C}$ from outside the village, and supplies labor $t_{h}^{C}$ to the farm household in the village. It may appear somewhat strange to suppose an intra-village labor market in a model with a representative household. This was designed to capture the intra-village employment of male household members that actually exists. We assumed that the CES labor production function with imperfect substitutability between $t D_{m}^{O}$ and $t D_{o}^{C}$ gave the labor market equations below:

$$
\begin{gathered}
t_{h}^{C}=\gamma\left(\delta_{m}^{O} t D_{m}^{O \eta}+\delta_{O}^{C} t D_{o}^{C \eta}\right)^{1 / \eta}, \\
t D_{m}^{O}=\left(\frac{y^{\eta} \delta_{m}^{O} p_{h}^{C}}{p_{m}^{O}}\right)^{1 /(1-\eta)}, \\
t D_{o}^{C}=\left(\frac{y^{\eta} \delta_{O}^{C} p_{h}^{C}}{p_{o}^{C}}\right)^{1 /(1-\eta)},
\end{gathered}
$$

where $p_{o}^{C}$ is the wage of $t D_{o}^{C}, \delta_{m}^{O}$ and $\delta_{O}^{C}$ represent input-ratio coefficients of the inputs, respectively, and $\delta_{m}^{O}+\delta_{O}^{C}=1$. The parameter $\gamma$ is the scale coefficient of the production function and $\eta$ is the coefficient of the elasticity of substitution $\sigma$. Here, to consider the effects of the Southeastern Anatolia Project, it was assumed that the labor supply from outside the village is fixed at $t_{o}^{C}$ and that the wage rate is determined at the point where $t_{o}^{C}$ and the demand for labor is crossed.

Finally, a restriction was imposed that the demands for goods/factors in some sectors and supplies of those in other sectors ( $X D$ and $X$ for generalized description, respectively) are equal:

$$
X D=X \text {. }
$$

With these restrictions, the utility maximization problem of the household becomes the maximization problem of $\Psi$ :

$$
\begin{aligned}
\Psi= & \mathrm{U}+\mu_{\mathrm{m}}\left(T_{m}-t_{m}^{C}-t_{m}^{L}-t_{m}^{O}-l_{m}\right) \\
& +\mu_{f}\left(T_{f}-t_{f}^{C}-t_{f}^{L}-t_{f}^{H}-l_{f}\right) \\
& +\mu_{\pi}\left\{p^{C}\left(q^{C}-x^{C}\right)+p^{L}\left(q^{L}-x^{L}\right)\right. \\
& \left.+p_{m}^{O} t_{m}^{O}-p_{r} a_{r}-p_{k}^{C} k^{C}-p_{k}^{L} k^{L}-p_{h}^{C} t_{h}^{C}-p_{x} x\right\},
\end{aligned}
$$

where

$$
\begin{gathered}
U=Z\left(x^{C}, x^{L}, x, t_{f}^{H}, l_{m}, l_{f}\right), \\
q^{C}=F^{C}\left(t_{m}^{C}, t_{f}^{C}, t_{h}^{C}, a, k^{C}, E_{k}^{C}\right), \\
q^{L}=F^{L}\left(t_{m}^{L}, t_{f}^{L}, k^{L}, E_{k}^{L}\right) .
\end{gathered}
$$

Endogenous variables here are $x, l_{m}, l_{f}, t_{m}^{C}, t_{f}^{C}, t_{m}^{L}$, $t_{f}^{L}, t_{m}^{O}, t_{h}^{C}, k^{C}, k^{L}, \mu_{m}, \mu_{f}, \mu_{\pi}$. Partial differentiation with these variables gives factor demand functions for each variable. In addition, $\partial \Psi / \partial \mu_{m}=0$, $\partial \Psi / \partial \mu_{f}=0$, and $\partial \Psi / \partial \mu_{\pi}=0$ give time allocation equations for male and female members and the budget constraints equation. Finally, the base model is explained by these equations, the rent function of the land-lease market, and the equations of the labor market.

\section{Acknowledgements}

The author gratefully acknowledges the financial support provided by the research project on the Impact of Climate Change on Agricultural Production Systems in Arid Areas (ICCAP), JSPS Grants-in-Aid for Scientific Research: Grant Number 25245047, 25850158, 26850147, and the Asahi Glass Foundation under Research Encouragement Grant for Humanities and Social Sciences.

\section{References}

Akerlof, G. (1980) A Theory of Social Custom, of Which Unemployment May Be One Consequence, The Quarterly Journal of Economics, 94: 749-775.

Arndt, C., S. Robinson, and F. Tarp (2006) Trade Reform and Gender in Mozambique, Nordic Journal of Political Economy 32: 73-89.

Brooks, J., M. Filipski, E. Jonasson, and J.E. Taylor (2010) Modelling the Distributional Impacts of Agricultural Policies in Developing Countries: The Development Policy Evaluation Model (DEVPEM), OECD Food, Agriculture and Fisheries Papers, 50. Paris: OECD Publishing.

Çakmak, E.H. (2004) Structural Change and Market Opening in Agriculture: Turkey towards EU Accession, ERC Working Papers in Economics, 0410. Ankara: Economic Research Center, Middle East Technical University.

Dyer, G.A., S. Boucher, and J.E. Taylor (2006) Subsistence Response to Market Shocks, American Journal of Agricultural Economics 88: 279-291.

Filipski, M., J.E. Taylor, and S. Msangi (2011) Effects of Free Trade on Women and Immigrants: CAFTA and the Rural Dominican Republic, World Development 39: 1862-1877.

Fletschner, D. and M.R. Carter (2008) Constructing and Reconstructing Gender: Reference Group Effects and Women's Demand for Entrepreneurial Capital, The Journal of Socio-Economics 37: 672-693.

Fontana, M. and A. Wood (2000) Modeling the Effects of Trade on Women, at Work and at Home, World Development 28: 1173-1190.

Hoshiyama, S. (2003) Female Inferiority and Gender Division of Labor: 'Ayip' ('Shamefulness') in Turkish Rural Society, Forum of International Development Studies 24: 95-111 (in Japanese).

Hosoe, N., K. Gasawa, and H. Hashimoto (2010) Textbook of Computable General Equilibrium Modeling: Programming and Simulations. Basingstoke: Palgrave Macmillan. 
Kagatsume, M. (2006) Impacts of Climate Change and the EU Accession on Turkish Rural Industries by the Input-Output Model and Markov-Transition Matrix, in The Research Project on the Impact of Climate Changes on Agricultural Production System in Arid Areas, The Advance Report of ICCAP. Kyoto: Research Institute for Humanity and Nature.

Kameyama, H., E.H. Çakmak, and Y. Lu (2007) The Economic Impact of EU Membership on Agriculture in Turkey, Technical Bulletin of Faculty of Agriculture, Kagawa University 59: 27-43 (in Japanese).

Kevane, M. and B. Wydick (2001) Social Norms and the Time Allocation of Women's Labor in Burkina Faso, Review of Development Economics 5: 119-129.

Maru, T. (2010) Agricultural Productivity and the Constraints on Female Labor Supply in Turkey, Journal of Rural Problems 46: 148-153 (in Japanese).

Morvaridi, B. (1992) Gender Relations in Agriculture: Women in Turkey, Economic Development and Cultural Change 40: 567-586.

Morvaridi, B. (1993) Gender and Household Resource Management in Agriculture: Cash Crops in Kars, in P. Stirling, ed., Culture and Economy: Changes in Turkish Villages. Huntingdon: The Eothen Press.

OECD (2011) Evaluation of Agricultural Policy Reforms in Turkey. Paris: OECD Publishing.

Sadoulet, E. and A. de Janvry (1995) Quantitative De- velopment Policy Analysis. Baltimore: Johns Hopkins University Press.

Taylor, J.E., A. Yunez-Naude, and S. Hampton (1999) Agricultural Policy Reforms and Village Economies: A Computable General-Equilibrium Analysis from Mexico, Journal of Policy Modeling 21: 453-480.

Turkish Statistical Institute (2007) Agricultural Structure: Production, Price Value 2004. Ankara.

Turkish Statistical Institute (2013) Women in Statistics 2012. Ankara.

USDA Foreign Agricultural Service (2004) EU-25 Agricultural Situation: Enlargement of the Common Agricultural Policy 2004, GAIN Report, E34004.

van Leeuwen, M., P. Salamon, T. Fellmann, A. Koç, G. Bölük, A. Tabeau, R. Esposti, A. Bonfiglio, A. Lobianco, and K. Hanrahan (2011) Potential Impacts on Agricultural Commodity Markets of an EU Enlargement to Turkey: Extension of the AGMEMOD Model Towards Turkey and Accession Scenario, JRC Scientific and Technical Reports, JRC60663.

Vendrik, M.C.M. (2003) Dynamics of a Household Norm in Female Labour Supply, Journal of Econom ic Dynamics \& Control 27: 823-841.

(Received August 2, 2014; accepted February 6, 2016) 